\title{
Research on Application Strategy of BIM Technology in Construction Project Management
}

\author{
Longbo Zhang ${ }^{1}$, Hao Liu ${ }^{2}$ \\ ${ }^{1}$ Dalian Vocational \&Technical College (DaLian Radio and TV University); Dalian, Liaoning Province, 116035 \\ ${ }^{2}$ China Construction Eighth Engineering Bureau Co., LTD. Northeast Company; Dalian, Liaoning Province, 116035
}

\begin{abstract}
BIM technology can participate in the entire process of building construction projects, using a three-dimensional way to restore all links involved in the process of building production. This intuitive and clear presentation method helps architects correct and quickly repair existing loopholes in a timely manner, ensure the smooth development of construction projects, improve efficiency and reduce losses due to project delays.
\end{abstract}

\section{Introduction}

The development of BIM technical management methods suitable for enterprises can not only promote the data connection between information simulation analysis and construction projects, but also improve management and production efficiency and bring more benefits. We should promote the use of BIM technology in the whole industry, cultivate employees' thinking mode of BIM three-dimensional model, and be patient and confident to promote the combined use of BIM technology with construction. BIM technology should give play to its advanced nature. As the information hub of a construction project, BIM technology should look at the overall situation and proceed to the details, and comprehensively cover the design, construction and subsequent maintenance of the entire project. Enterprises can also use BIM technology to optimize management, realize automatic control and information management assembly in production, and truly give play to the advanced productivity of BIM technology.

\section{Concept of BIM Technology}

BIM is the first letter of English Building Information Modeling, which translates to the meaning of building information model. BIM does not specifically refer to a certain piece of software but an industry concept, in which the technology and management software is only his application platform. BIM is the use of digital technology to simulate the construction of a building. It uses a visual interface to input the information of various components of the building into the computer, and then calculates and analyzes the statistics by the computer. It intuitively provides designers with relevant data in various stages of design, construction and maintenance. BIM technology can realize information sharing between three-dimensional design and different professional designs, perform virtual intelligent design, conduct collision experiments, and conduct energy cost analysis. BIM technology can refine the manpower, resources, equipment, site and other dynamic information required by the simulation construction project. This will help us grasp the progress of construction and realize the visual simulation management of the construction process. BIM technology can also simulate the construction process of the building to analyze potential problems in the construction and optimize the design plan.

In the practical application of construction management, BIM technology is mainly used for drawing refinement. BIM technology uses three-dimensional parametric models to provide specific information on geometry, materials, and schedules for construction management design, and integrates information when the design drawings are finalized. The system can automatically produce design drawings and corresponding required raw material reports, assist the design department to grasp the overall picture of the project, and help the purchasing department understand the overall cost of the project. The significant advantage of BIM technology is that it realizes the overall coordination and visibility of architectural design, which greatly changes the status quo of traditional architectural drawing construction relying on the imagination of architects to complete drawing models. BIM can directly convert the model in the architect's mind into three-dimensional graphics, and realize the three-dimensional display of internal structure data. This modeling method can complete internal structure and related data analysis to a certain extent. For example, in the design of air conditioning and ventilation engineering inside the building, the location of the air conditioning vents can be reasonably arranged. The BIM system can realize the interoperability of information and ensure that there will be no deviation during the exchange and transmission of information. The data information 


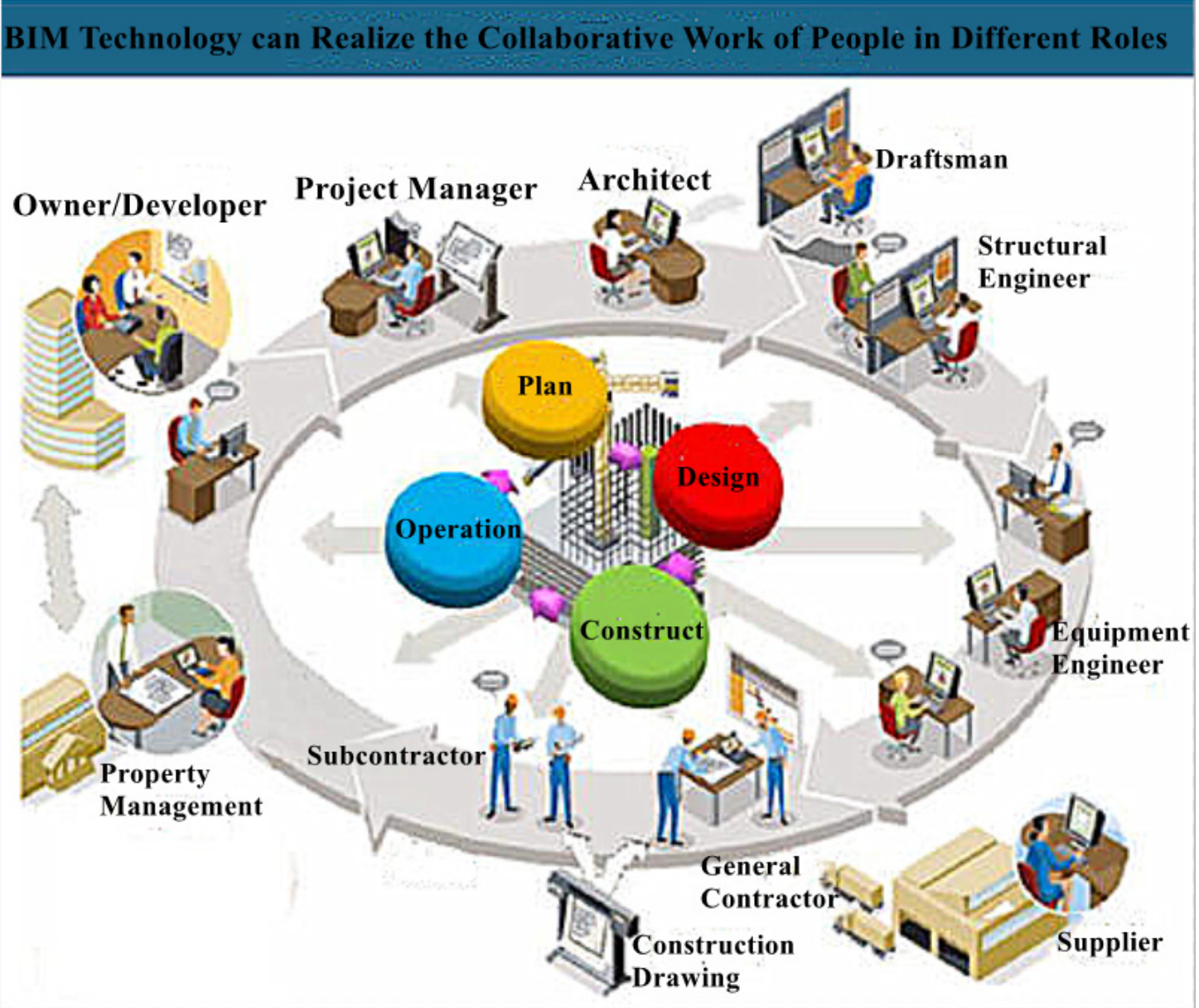

Figure 1: BIM Simulation System

\section{Advantages of BIM Technology}

\subsection{Extensive Data Support}

The data formats supported by BIM as platform software mainly include international IFC standard software and construction-related data analysis. BIM analysis of other data types needs to be converted into a data format supported by the platform. We need to convert the corresponding model format to $\mathrm{E} 5 \mathrm{D}$ format before analysis. In the same way, for the calculation of civil construction steel bar model and civil construction related data, we need to convert it to igms format before proceeding to use the platform for analysis. The platform has an ideal use effect on some software formats, and it can ensure that the analysis is performed on the premise that all the data is intact. Compared with the previous BIM software Revit, there is a big improvement in the loss of data during data exchange. Practical research has proved that BIM has weak data support for part of the modeling software and has harsh completion conditions. The modeling data analyzed by BIM needs to name the components according to the data format supported by the platform and set the value of the components, otherwise the platform cannot reasonably analyze and recognize the image of the input data. Once the platform data is entered, the relevant parameters of the model cannot be corrected. If we want to change the numerical value of the model, we need to model again, change the data format, and re-enter the BIM 5D platform to complete the model change.

Part of the project construction requires the use of RevitMEP model, Glodon Rebar Model, Glodon Civil Engineering Calculation Model. When the final data is summarized and input into the BIM system, there will be errors due to different actual measurement targets of each data and different software types. At this time, we need to manually modify the data of each target base point to make it perfectly consistent with reality.

\section{The Necessity for BIM to Participate in Project Management}

Project construction management plays an extremely important role in building quality, building cost and subsequent building quality monitoring, and the progress of construction projects. Only effective project management can ensure the safety and quality of the construction process. Starting from the details and 
starting from the root of the project is conducive to achieving a multi-level grasp of the progress of the project construction in all aspects and fields. This can ensure the accuracy of each link, and then achieve the overall effect of the lowest cost and the best quality. Simultaneously, this is also conducive to improving the competitiveness of their own enterprises in the industry, and stand out in the increasingly fierce industry competition.

\subsection{Reasonable Design Engineering Plan}

Reasonable design of the project plan should pay attention to the overall project schedule. We must not only rationally arrange the task amount for each day within the specified number of construction days, but also include the missed work caused by related accidents. We also need to refine the entire construction plan to the installation arrangement of a small blind. When formulating the plan, we should also consider the project cost of the entire project to estimate the project's advance expenditure and other expenditures such as fixed assets, design costs and other expenditures. The company's assessment of the entire project includes various needs such as income and expenditure. From the beginning of the design of the project to the final acceptance of the entire project, the various expenditures required for all the process details are covered in the entire project cost.

BIM technology can use its own multiple design software support (Tekla Structure, Stru-CAD, etc.) to assist the refinement of steel structure design. It focuses on the details and can ensure that there will be no problems in subsequent processing and on-site assembly. Such detailed design drawings can help guide the construction personnel to correctly carry out construction and maintenance operations. The drawing designer can enter the real size into the two-dimensional simulation interface of the steel structure for modeling according to the actual needs. Designers can adjust the perspective to check the problems in the modeling operation according to their own preferences. The automatic error correction system of the software itself can assist the designer in checking and avoid the occurrence of low-level errors. After confirming that the modeling is accurate, the software will automatically generate detailed design drawings of the steel structure construction according to the actual needs of the user. Compared with the plane CAD technology, the drawing efficiency of BIM technology has been greatly improved. Among them, the detailed drawings that Tekla Structure can design include 3D layout drawings, floor layout drawings, parts drawings, node details, and component drawings. In the mean time, the software itself can automatically generate reports for the required materials such as the force of the plate, the area of paint applied, and the required number of ground anchor bolts.

\subsection{Scientific Selection}

The construction materials for the construction of the project account for a large proportion of the overall cost.
Therefore, we need to select raw materials scientifically and reasonably to avoid problems such as material quality problems or excessive or insufficient quantities of materials that drag down the progress of the entire project. Never drag down the entire project progress as the starting point and ultimately achieve the goal of reducing the overall project construction cost. The construction material cost of the project construction mainly includes all the material costs needed in the construction of the entire project, such as the purchase of raw materials, construction machinery and equipment, and backup materials. Before purchasing materials, we must review and consider the actual conditions of the construction site and carefully select materials. In addition to carefully comparing the prices of various materials, we also need to conduct a strict review of the quotations, performance, and quality of various building materials to prevent overfilling and shoddy phenomena. For the long-term benefit, we will take the additional costs of maintenance and replacement into account and consider the selection of materials. Choose local suppliers as much as possible to reduce transportation costs, and you may not purchase materials that are temporarily unused. For one thing, this is helpful to prevent capital occupation, for another, it is mainly to save costs and avoid waste caused by buying too much. The person in charge of the project must establish a strict review and supervision system to prevent waste of materials during construction from causing unnecessary costs to the construction of the project. Take the selection of steel structure parts as an example. Unlike mechanical manufacturing, steel structure processing and manufacturing rely almost entirely on manual supervision in production management. These include checking drawings, checking the processing flow, and supervising the production process. In this way, there will be mistakes and management confusion, and then some human errors will occur. The fact that labor cannot keep track of material supply, the normal operation of machines, and the processing level of workers are the actual factors that affect the quality of steel structure production. Such costs are too high and can not achieve the expected satisfactory results. This requires us to establish a systematic and intelligent production management system in steel structure manufacturing enterprises. BIM technology can provide basic data needed for information production for steel structure manufacturers. The BIM software records and stores the data information generated in each process of steel structure processing and production, so that the corresponding information can be smoothly read in the operation terminal of the machine. In this way, delays in the gradual transmission of traditional enterprise production orders can be avoided. Furthermore, in this way, not only can the data required for production be directly transmitted to the corresponding production department, but also the production data information can be fed back in time, and the information transmission and feedback can be smoothly realized. 


\subsection{Construction Quality and Safety Management}

BIM defines a new quality and safety management method for marking issues. The traditional steps to solve quality and safety management problems are to find construction problems, record in detail, issue paper notices, arrange for manual handling in a timely manner, check and accept the processing quality, and complete the problem processing.

Compared with the previous technological innovation, BIM uses an intuitive way of visually marking problems, so that the relevant construction personnel can find the problem in time and take timely solutions after implementing the model import. BIM technology can mark the position to be processed corresponding to the record model, realize the real-time change of the mark and keep real-time synchronization with the BIM database. This not only facilitates the on-site construction personnel to understand the on-site condition as soon as possible after receiving the processing notice, but also facilitates the development of the next construction and repair work.

After confirming that the problem is eliminated, the BIM platform is used to mark the target location of the problem as processed, and the data is synchronized and updated to help on-site quality inspectors to clarify the situation for verification. BIM technology can also use the mobile terminal of mobile phones for data collection and timely verification of the actual quality of each target building, facilitating the acceptance work and subsequent operation and maintenance.

\subsection{Construction Progress Supervision}

BIM realizes construction progress supervision through the comparison and analysis of the summary design of the total plan and the actual plan implementation. After importing the construction model into BIM, it also makes a reasonable correlation with the planning documents prepared first. Refine the entire construction plan to demonstrate the planning progress of each stage in sections, and combine the development requirements of each time node to simulate and analyze the data of the target object of BIM for detailed feedback. Use BIM to feed back actual project progress to compare the difference between planned and actual progress. Even if the pace of implementation of the plan is adjusted, the smooth implementation of the target is guaranteed. The specific presentation method is that the project manager at the construction site records the construction progress data, and uses time as a comparison parameter to achieve a horizontal comparison of the overall time axis.

\subsection{Practical Application of Construction Material Management}

Based on the basic model, BIM analyzes the quantity of materials for the total project construction to assist the management of the construction materials of the project. The software can refine each specific part of the construction to query the total required quantity of all construction materials of different types. The BIM technology will arrange to form a summary material report based on the number of materials provided by the software combined with actual needs. Then, under the premise that the data is accurate, scientific and reasonable, the schedule management is implemented. With the continuous advancement of construction progress, it provides reference basis for project management personnel and controls materials.

\subsection{Project Cost Control Management}

BIM is mainly used as a software service platform for project cost and salary fund management. It can achieve a good compatibility model with previous engineering cost software, and assist enterprises in formulating excellent engineering cost plans. Combining the cost settlement results obtained by labor according to the actual construction situation, a tripartite result comparison is formed from the contract cost, the actual cost, and the settlement cost. BIM technology will compare and analyze the use of funds to predict the profit and loss of the project based on the real-time market price changes and the progress of the project, and deal with it in a timely manner to reduce the risk and loss. Finally, BIM technology will positively associate the model entity with the actual material, labor and other expenditure lists. The BIM system contains a variety of association methods for analysts to choose, so that both component association and automatic association can be realized.

\section{Conclusion}

In order to strengthen the construction management of construction projects, we can borrow the technical advantages of BIM to analyze the huge information database. Moreover, we can also pay attention to the details of the design while designing the scheme, and fully grasp the characteristics of the entire project. From the beginning of the design and drafting of the project to the final settlement of the project, the use of BIM technology and scientific planning of the work process and material use in each link can eliminate unscientific design costs. Furthermore, we are supposed to strictly follow the design drawings to avoid frequent changes to the construction design, which can reduce the possibility of construction delays and improve the quality of construction projects.

\section{Acknowledgement}

2018 Science and Technology Innovation Project of Dalian Vocational \& Technical College

2019 Scientific Research and Innovation Fund Program of Dalian Vocational and Technical College 


\section{References}

1. Ni Hong. Application practice of BIM technology in the construction of housing construction projects[J]. Building materials and decoration, 2020(21):1+3.

2. Du Wenhui. Research on the application of BIM technology in construction project management[J]. Value Engineering, 2019, 38(34): 280-281.

3. Pang Donghui. Research on the application of BIM technology in construction project management[J]. Urban Architecture, 2019, 16(33): 113-114.

4. Zhang Shoubiao. Application analysis of BIM technology in construction progress forecasting and management of construction projects[J]. Housing and Real Estate, 2019(31): 123.

5. Lin Cong. The application of BIM technology in building construction[J]. Doors and Windows, 2019(20): 51.

6. Qin Feng. The application of BIM technology in the teaching of construction project management[J]. Building Materials and Decoration, 2018(43):141-142.

7. Li Zhipeng. The application of BIM technology in the teaching of construction project management in secondary vocational schools $[\mathrm{J}]$. Contemporary Teaching Research Collection, 2018(04):132-133.

8. Zhu Shuo. The application of BIM technology in the teaching of construction project management in secondary vocational schools $[\mathrm{J}]$. Talent, 2017(15):142.

9. Shi Xiaoqing, Yang Gongquan, Wang Xiaoyong. Analysis of the application of BIM technology in construction project management $[\mathrm{J}]$. Anhui Architecture, 2016, 23(06): 180-181+187. 